ISSN 2359-1412

http://dx.doi.org/10.21438/rbgas.030500

\title{
Revista Brasileira de Gestão Ambiental e Sustentabilidade
}

\begin{tabular}{lll}
\hline Volume 3 & Setembro, 2016 & Número 5 \\
\hline
\end{tabular}

\section{Editorial \\ V Congresso Brasileiro de Educação Ambiental Aplicada e Gestão Territorial}

\section{Francisco Otávio Landim Neto}

Comissão cientifica do V CBEAAGT. Universidade Federal do Amapá - UNIFAP. Campus Binacional. Rodovia BR-156, $\mathrm{n}^{\circ}$ 3051. Bairro Universidade. Oiapoque-AP (CEP 68980-000). E-mail: otaviogeo@oi.com.br.

O V Congresso Brasileiro de Educação Ambiental Aplicada e Gestão Territorial - V CBEAAGT foi sediado na Universidade Federal do Ceará, Departamento de Geografia, Campus do Pici, em Fortaleza, no período de 8 e 11 de julho de 2016. Promoveram-se debates, sendo elencadas experiências acadêmicas em nível local, regional e nacional, buscando contribuir com a difusão de ideias e trabalhos que buscaram a construção de uma sociedade mais sustentável.

Assim, tratou-se de um momento singular no contexto nacional, com espaços destinados à discussão e à troca de conhecimentos atrelados aos temas relacionados com o congresso que foi constituído por um conjunto de palestras, minicursos e apresentações de trabalhos acadêmicos e técnicos. Este evento envolveu parcerias entre a Universidade Federal do Ceará - UFC (Programa de Pós-Graduação em Geografia - PPGe e Programa de Desenvolvimento e Meio Ambiente - PRODEMA) e mais 14 universidades públicas brasileiras e três estrangeiras, a saber, Universidade de Havana (Cuba), Universidade de Coimbra (Portugal) e Universidade Cabo Verde (Cabo Verde) incluindo seus respectivos programas de graduação e pós-graduação e grupos de pesquisa.

Em relação à organização dos trabalhos acadêmicos e técnicos o V Congresso Brasileiro de Educação Ambiental Aplicada e Gestão Territorial foi constituído por três grandes áreas
Recebido

29/07/2016

Aceito

$31 / 08 / 2016$

Publicado

30/09/2016

Acesso aberto Artigo completo

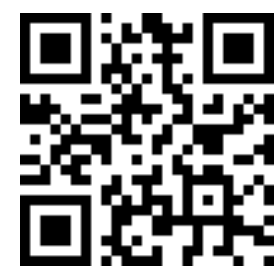

ORCID

(1) 0000-0002-0580-3852

Francisco Otávio

Landim Neto

com seus respectivos eixos temáticos, a saber, i) Área 1: Educação Ambiental Aplicada, que abrangeu o Eixo 1: Educação ambiental, sustentabilidade e gestão comunitária, o Eixo 2: Educação Patrimonial e cultura afrobrasileira e indígena, e Eixo 3: Ecopedagogia na educação 
formal e informal; ii) Área 2: Gestão territorial em escala local e regional, foi constituída pelo Eixo 4: Sociobiodiversidade e biotecnologias alternativas, Eixo 5: Bacias hidrográficas: planejamento e gestão ambiental, Eixo 6: Planos diretores e políticas culturais e territoriais, e pelo Eixo 10: Planejamento, gestão ambiental e desenvolvimento sustentável; e iii) Área 3: Cartografia social na representação de conflitos territoriais composta pelo Eixo 7: Territórios, populações tradicionais e conflitos sociais, Eixo 8: Geotecnologias aplicadas à gestão ambiental participativa, e pelo Eixo 9: Cartografia temática aplicada em áreas de risco.

No sentido de oportunizar a ampla divulgação dos melhores artigos científicos enviados ao V CBEAAGT, foi realizada uma parceira com 15 periódicos eletrônicos que se dispuseram a publicar edições especiais com os artigos indicados pela comissão cientifica do referido evento. Nesse contexto a Revista Brasileira de Gestão Ambiental e Sustentabilidade publica nesta edição os melhores quatorze artigos enviados para a Área 2 do V CBEAAGT.

O primeiro artigo foi elaborado por Cecília Barreto Rodrigues, Marcio Regys Rabelo de Oliveira, Patrícia Verônica Pinheiro Sales Lima e Francisco Casimiro Filho, intitulado "Instrumentos de gestão ambiental em municípios do semiárido brasileiro", analisa o nível de implementação de instrumentos de gestão ambiental nos municípios do Semiárido Brasileiro ( $\mathrm{SAB}$ ) levando em consideração: i) a possibilidade de análise de todo Semiárido Brasileiro (SAB), ii) a sistematização de informações importantes para a compreensão do papel dos municípios na minimização dos problemas ambientais do SAB; iii) a identificação dos municípios com menores e maiores níveis de implementação de instrumentos de gestão ambiental, e iv) a identificação dos instrumentos que estão sendo implementados. O estudo constatou que os modelos de gestão do meio ambiente nos municípios do semiárido brasileiro apresentam fragilidades inerentes ao baixo nível de implementação de instrumentos de gestão.

O segundo artigo, escrito por Ana Paula Pinto Bastos, intitula-se "Práticas de Educação Ambiental em escolas públicas de Praia, Cabo Verde", trata de um estudo que visa a disseminar as práticas ambientais em três escolas, para que esses ambientes educacionais possam construir uma relação de ensino e aprendizagem significativa. É feito um diagnóstico sobre as dificuldades das práticas ambientais nas escolas pesquisadas em Praia sendo que se pode elencar, i) os habitantes demonstraram estar mais preocupados com a grande falta de água na cidade de Praia, fato que compromete a limpeza das ruas, das residências e das escolas, ii) sujeira provocada pelo comércio informal que existe no entorno de escolas, casas, etc, iii) ausência de calçadas nas margens dos arruamentos, iv) nas escolas, as crianças e jovens não possuem o material escolar necessário para sua aprendizagem, as bibliotecas muito precárias, e v) a saúde, habitação e qualidade de vida são aspectos que merecem maior cuidado e relevância por parte dos gestores locais no sentido de elaboração e aprovação de projetos nos setores responsáveis.

O terceiro artigo foi construído por Francimilo Gomes Santos da Silva, Francisco Pereira da Silva Filho, Diego Silva de Oliveira, Haizza Danielle Silva Dias e Edvania Gomes de Assis Silva, sendo denominado "A Educação Ambiental como instrumento de gestão turística sustentável na Praia da Pedra do Sal, Parnaíba (Piaui)”, visa a verificar os instrumentos de Educação Ambiental que promovam a gestão sustentável do turismo municipal, apresentando uma discussão sobre a importância e os princípios da Educação Ambiental na sociedade, são identificados problemas ambientais relacionados à atividade turística na Praia da Pedra do Sal. Constatou-se que a referida praia necessita de uma maior presença do poder público na gestão da atividade turística, levando em consideração que a Educação Ambiental afigura-se como instrumento de gestão cabendo aos governos à responsabilidade de promover qualidade de vida à população e aos visitantes, visando a possibilitar a efetivação do turismo sustentável na região.

O quarto artigo escrito pelos pesquisadores Huáscar Pinto Vidal de Oliveira e Edson Vicente da Silva, intitula-se "Sistemas ambientais e vulnerabilidade à degradação dos recursos naturais dos municípios do Baixo Jaguaribe com aplicação de geotecnologia: subsídios ao 
ordenamento territorial”, analisa os sistemas ambientais, suas vulnerabilidades à degradação em face do uso da terra, nos municípios do Baixo Jaguaribe do Estado do Ceará, através das geotecnologias. Constaram que dentre os seis sistemas ambientais delimitados para o Baixo Jaguaribe, a planície litorânea é o mais instável com vulnerabilidade alta à ocupação, abrangendo mais da metade de toda a área. Os tabuleiros pré-litorâneos são estáveis em condições de equilíbrio natural com vulnerabilidade baixa à ocupação demonstrando potencialidades para a expansão urbana e para a prática de outras atividades. A delimitação e caracterização dos sistemas ambientais, distinguindo sua capacidade de suporte e dinâmica ambiental, podem contribuir para o diagnóstico da dimensão socioambiental e prever cenários tendenciais.

O quinto artigo foi elaborado por Paulo Roberto Mendes Pereira, Taíssa Carolina Silva Rodrigues e Josué Carvalho Viegas, é denominado "Diagnóstico ambiental e caracterização morfométrica das Microbacias Hidrográficas de Pedro do Rosário - Amazônia Maranhense (Brasil)", objetiva identificar as características morfométricas de um conjunto de microbacias hidrográficas localizadas no Município de Pedro do Rosário, a noroeste do Estado do Maranhão. Constatou-se que as microbacias estudadas apresentaram baixa densidade de drenagem, e rios com baixa energia. Além disso, apresenta em seu percurso canais em sua maioria retificados, outro fator identificado se refere à fraca capacidade de geração de novos canais e grande número de canais de primeira ordem.

O sexto artigo foi feito pelos pesquisadores Renato Oliveira Barros e Ernane Cortez Lima, intitulado "Compartimentação geomorfológica da Sub-Bacia Hidrográfica do Riacho Bilheira, Taperuaba-CE, como subsídio ao planejamento ambiental”, realiza a compartimentação geomorfológica da Sub-Bacia Hidrográfica do Riacho Bilheira como subsídio ao planejamento ambiental. Constatou-se que a área em estudo possui três unidades geomorfológicas, são elas Inselbergues, Planície Fluvial e Depressão Sertaneja. Há uma descaracterização acentuada da mata ciliar, solos desnudos, assoreamento das nascentes de riachos e desmatamentos indiscriminados da cobertura vegetal natural. A compartimentação geomorfológica servirá como ferramenta importante para analisar a degradação ambiental e afigura-se como aporte metodológico para subsidiar ações voltadas para o planejamento ambiental.

O sétimo artigo foi escrito por Cleciane Rodrigues Martins e Ernane Cortez Lima, denominado "Análise do uso e ocupação do solo e seus aspectos socioambientais na Sub-Bacia Hidrográfica do Rio Contendas, Massapê-CE", realiza uma análise referente ao uso e a ocupação do solo da Sub-Bacia Hidrográfica do Rio Contendas, no Município de Massapê, localizada na região noroeste do Estado do Ceará, ocupando uma área de $111 \mathrm{~km}^{2}$. Verificou-se o intensivo processo de ocupação na sub-bacia, que necessita de ações efetivas dos atores municipais para melhor gestão dos recursos naturais. O trabalho é importante para complementar as pesquisas sobre a área de estudo e pode subsidiar propostas voltadas à melhoria da qualidade dos recursos naturais da sub-bacia e consequentemente a vida da população que utiliza os recursos hídricos locais.

O oitavo artigo foi elaborado por Francisco Johnson Albuquerque Batista, José Ribeiro de Araújo Neto, Helba Araújo de Queiroz Palácio, Geovane Barbosa Reinaldo Costa e Maria Monaliza de Sales, intitula-se "Impacto da ação antrópica na degradação da mata ciliar do trecho perenizado do Rio Trussu, Ceará, Brasil”, avalia o impacto da ação antrópica na degradação da mata ciliar do trecho perenizado do Rio Trussu, no período de 2003 e 2013, por meio de técnicas de geoprocessamento. Conclui-se que o uso e a ocupação do solo no setor de mata ciliar do trecho perenizado da área de estudo apresentou maior percentual de classificação de área antropizada nos dois períodos de avaliação, seguidos pelas classes de Caatinga densa e rala. Verificou-se ainda a existência de uma dinâmica acelerada no comportamento da cobertura vegetal com a substituição progressiva das áreas de Caatinga densa por áreas de Caatinga rala e 
antropizada, evidenciando uma progressiva degradação sobre os recursos naturais nestes setores durante os anos pesquisados.

O nono artigo foi escrito por Matheus Magalhães Silva Moura, Geovane Barbosa Reinaldo Costa, Helba Araújo de Queiroz Palácio, José Ribeiro de Araújo Neto e José Bandeira Brasil, sendo denominado "Produção de serapilheira e suas frações em área da Caatinga no Semiárido Tropical”, avalia a deposição da serapilheira e suas frações folhas, galhos, estruturas reprodutivas e miscelânea em área da Caatinga Nativa, verifica-se também a interferência de variáveis climáticas, desenvolveu-se um estudo em uma microbacia experimental localizada no município de Iguatu, Ceará, Brasil. Este estudo concluiu que a produção de serapilheira de folhas apresenta uma total relação com o regime pluviométrico, sendo que seu ápice de produção ocorre logo após a quadra chuvosa. Já a fração inerentes aos galhos é observado uma redução na deposição dessa fração à medida que se encerra a quadra chuvosa e durante a época seca do ano, vindo a aumentar com o avanço da nova quadra chuvosa. A fração miscelânea que se fez presente em todos os meses do estudo, apresenta leve tendência de aumento de deposição, iniciando no meio da quadra chuvosa e prolongando-se até a transição com a estação seca. A produção de serapilheira total afigura-se de caráter sazonal, com picos de produção imediatamente posterior à quadra chuvosa.

O décimo artigo, escrito por Murilo Cezar Cucolo, Milene Harumi Tomoike, Edison Schmidt Filho, Isabele Picada Emanuelli e Luiz Felipe Machado Velho, é intitulado "Influência da aplicação de vinhaça e cinza de caldeira tratados por Processo $\mathrm{N}$-Viro sobre a população microbiana do solo de Maringá-PR”, objetiva discutir as relações entre os resíduos da produção sucroalcooleira e os componentes químicos do solo visando a uma destinação apropriada e sustentável. Após a incubação das placas de Petri foram avaliados o crescimento dos microrganismos, sobre as diferentes concentrações da vinhaça e cinza de caldeira tratados por Processo N-Viro, de períodos de 24 e 48 h. Conclui-se que se faz necessário uma avaliação prévia da interação entre as diferentes doses de vinhaça e cinza de caldeira tratados por Processo N-Viro aplicadas no solo e sua relação nas populações microbianas existente nas amostras de solos.

O décimo primeiro artigo foi elaborado por Danyella Vale Barros, Quésia Duarte da Silva, Estevânia Cruz Teixeira, Cristiane Mouzinho Costa e Ricardo Gonçalves Santana, sendo intitulado "Morfometria e uso e cobertura do solo como indicadores de enchentes e inundações na Bacia do Rio do Prata, Ilha do Maranhão", analisa algumas variáveis morfométricas da Bacia Hidrográfica do Prata associadas às classes de uso e cobertura do solo, afim de se identificar à sujeição da ocorrência dos fenômenos de enchentes e inundações. Constatou-se que a instalação de diversas edificações nas planícies fluviais tem contribuído diretamente para ocorrência dos eventos em questão. Identificou-se ainda que uma das três sub-bacias identificadas apresenta maior sujeição aos fenômenos de enchentes e inundações, seja pelo uso da terra ou pelas características morfométricas.

O décimo segundo artigo foi escrito por Flávia Regina Sobral Feitosa, Ivana Silva Sobral, Maria do Socorro Ferreira da Silva, Edilma Nunes de Jesus e Haiane Pessoa da Silva, intitula-se "Planejamento e saúde: uma análise dos condicionantes socioambientais $e$ institucionais para prevenção e controle do Aedes aegypti em Aracaju”, analisa os condicionantes socioambientais e institucionais que interferem na prevenção e controle do Aedes aegypti no Município de Aracaju-SE. Constatou-se que a rede de prevenção e controle ao Aedes aegypti no município, embora formalmente consolidada, apresenta uma série de obstáculos para tornar efetiva a assistência no modelo preconizado pelo Sistema Único de Saúde (SUS), dentre os quais se pode citar o reduzido quantitativo de Agentes de Combate às Endemias e a frágil intersetorialidade entre os equipamentos e os serviços de saúde. Além disso, o deficitário sistema de ordenamento territorial, onde o atual plano diretor não contempla o uso e ocupação do solo de todas as áreas da capital, e a precariedade do saneamento ambiental são fatores que contribuem para o surgimento e disseminação de criadouros do mosquito. 
O décimo terceiro artigo foi elaborado por Haroldo Scacabarossi e Yasnara Silveira de Medeiros, é intitulado "A triagem e catação de recicláveis dentro do aterro sanitário como condicionantes de vulnerabilização social de excluídos em Boa Vista-RR", discute o delineamento conceitual da problemática inerente à triagem de recicláveis no Município de Boa Vista, no que diz respeito aos atores principais dos processos de catação e triagem praticados no interior do Aterro Sanitário de Boa Vista. Aborda uma discussão acerca da abordagem teóricometodológica das variáveis dos processos, frente às recentes transformações socioambientais ligadas ao tema. Constatou-se que se faz necessário a efetivação de uma série de medidas que vão desde a elaboração e implantação do Plano Municipal de Resíduos Sólidos, necessárias para a eliminação dos chamados lixões. Entende-se que as medidas propostas pelo Guia de Atuação Ministerial para o Encerramento de Lixões contemplam quase em sua totalidade, as inúmeras ações necessárias para a inclusão desses trabalhadores em uma melhor condição social.

Espera-se que esta edição especial da Revista Brasileira de Gestão Ambiental e Sustentabilidade contribua para a fortificação da compreensão teórica, conceitual e metodológica inerente a temática da gestão territorial em escala local e regional. Nesse sentido objetiva-se que sejam elencadas novas reflexões sobre a temática em questão o que contribuirá para construção do conhecimento integral referente aos problemas ambientais presentes nos territórios.

Informação da Licença: Este é um artigo Open Access distribuído sob os termos da Licença Creative Commons AtribuiçãoSemDerivações-SemDerivados, que permite o download do trabalho e o compartilhamento desde que seja atribuído o devido crédito, mas sem que possa ser alterado de nenhuma forma ou utilizá-los para fins comerciais. 